\title{
ON THE CAUSE AND PREVENTION OF DEATH FROM CHLOROFORM.
}

\author{
By JOHN SNOw, M.D.
}

\section{(Continued from p. 329 of last number.)}

ON looking over the list previously given, it will be seen that the accidents from the administration of chloroform nearly all occurred during, or preparatory to, minor operations. The case of extirpation of the eyeball, No. 13-that of amputation of the leg, No. 17, and the removal of the testis, No. 19, are the only operations of importance in the list. None of the accidents have happened in childhood or old age ; and, except the subject of amputation, case 17, and the last case in the list, none of the patients were reduced to a state of debility. The general health also of the twenty-one patients who lost their lives was probably better than the arerage state of it in the thousands who have inhaled chloroform without accident; for the greater number of them are stated to have been in good health, and, except Patrick Coyle, No. 4, who was suffering from phthisis, and the patient with cancer of the uterus, No. 21 , it has not been recorded that any of them were effected with serious disease of any internal organ. The reason of the accidents having happened under the conditions just named is probably that in large operations-in children and old people-in those much reduced by illness or affected with organic disease, an amount of care has been taken which has not always been observed under other circumstances; for, however faulty the method of administering the chloroform may be, the exercise of attention and care very much diminishes the danger, and it cannot be denied that there has been a want of care and attention in many of the cases in which accidents have happened. In the recent trial of a medical man at Strasbourg for homicide, by imprudence and want of precaution, in causing the death of a patient by chloroform, the President of the Tribunal made some very appropriate remarks on this point. He said, "When a patient is submitted to the action of chloroform, every attention ought to be fixed on the progress of the anæsthesia, and on the state of the pulse and respiration. Instead of that you extracted several teeth without having examined the state of your patient. You acted alone, whilst men of eminence constantly procure the aid of assistants." I In some of the cases all the care was certainly employed that the operator had been led to believe was necessary, and the accidents were entirely due to the faulty method of administering the chloroform.

In order to show clearly the cause of the deaths which have taken place, it is necessary to give an outline of the phenomena which occurred at the time of dissolution, in the cases of which the particulars are related. In the first case, in the list previously given, about a fluid drachm of chloroform was poured on a tablecloth, and held to the nose of the patient. Dr. Meggison, the medical attendant of the 
patient, said "in about half a minute I observed the muscles of the arm become rigid, and her breathing a little quickened, but not stertorous. I had my hand on her pulse, which was natural until the muscles became rigid. It then appeared somewhat weaker, not altered in frequency." The operation was now performed ; and when the semicircular incision was made, the patient gave a struggle or jerk. Regarding the state of the girl immediately afterwards, Dr. Meggison continues: "Her eyes were closed and I opened them, and they remained open. Her mouth was open, and the lips and face blanched. I called for water and dashed some of it in her face. I then gave her some brandy, a little of which she swallowed with difficulty." 1 Other means were used with the hope of restoring the patient, but without effect; and she was dead within two minutes from the commencement of the inhalation. During the operation, at the time of the jerk mentioned above, the patient made a prolonged forced expiration, during which the tongue was protruded from the mouth, and the remaining expirations and inspirations were exceed. ingly feeble and few. ${ }^{2}$ It will be remarked that the insensibility was induced so quickly in this case, that the air the patient breathed must have been charged with vapour of chloroform to a dangerous extent, and that the blood could not have been uniformly impregnated with the narcotic in so short a time as half a minute : the heart would therefore be liable to be paralysed by its direct action. The palor of the countenance renders it extremely probable that such was the case, although we have no direct proof of it, since Dr. Meggison and his assistant were too much occupied in endeavouring to restore the patient to ascertain whether there was any pulse after the alarming symptoms set in. I have often seen convulsive movements at the time of death in animals that were suddenly killed by chloroform.

Mrs. Simmons, of Cincinnati, the subject of the second fatal case, inhaled chloroform from an apparatus contrived by Dr. Morton, of Boston, for the inhalation of ether. It contained a sponge saturated with chloroform, and one-third filling the glass globe of four and a half inches in diameter. The breathing was at first slow, and the patient inhaled twelve or fifteen times, occupying from a minute to seventy-five seconds. She became pale whilst inhaling. As soon as the inhalation was left off four stumps of teeth were extracted: the patient groaned whilst this was taking place, and as the last stump came out, which was about two minutes from the commencement of inhalation, there was a kind of convulsive motion in the limbs and body. At this instant Mrs. Pearson, a friend of the patient, placed her finger on the pulse, and observed that it was very feeble, and almost immediately ceased to beat; respiration also ceased about the same time, according to her evidence, viz., about two minutes from the commencement of inhalation; but the dentists, who did not belong to the medical profession, considered that a longer time elapsed before death. ${ }^{3}$ It is probable from the palor of the face, which came on during inhalation, that the heart was affected by the direct action of the chloroform; but if the witness Mrs. Pearson was not mistaken

1 Lancet, 1848, vol. i, p. 161. 2 Med. Gaz., vol. xli, p. 277. 3 Med. Gaz., vol. xlii, p. 79. 
about the pulse, the heart did not altogether cease to beat till about a minute afterwards.

In the third case, that of the young woman at Hyderabad, a drachm of chloroform was administered in what the operator called the usual way, i.e., it was sprinkled on a handkerchief and inhaled. He described what occurred as follows:- "She coughed a little, and then gave a few convulsive movements. When these subsided, I performed the necessary incisions, which of course did not occupy more than a few seconds. Scarcely a drop of blood escaped." The operator, after mentioning the means which were used to recover the patient, without avail, continues, "I am inclined to think that death was almost instantaneous; for, after the convulsive movements above described, she never moved or exhibited the smallest sign of life."1 In this instance also death was evidently caused suddenly by the action of chloroform vapour not sufficiently diluted with air; and it seems, from the brief account of the case, that the breathing and action of the heart were arrested at the same moment.

In the fourth case, that of Patrick Coyle, Dr. Warren, who relates it, ${ }^{2}$ states that about thirty drops of chloroform were used, and that the time of inhalation, as also the lapse of time from the commencement of inhalation till death, was one minute. Speaking of the symptoms, he says that the patient "showed signs of pain, by putting his hand to the part; in a moment his pulse, which was full and natural, sank; death." The cause and manner of death were evidently the same as in the last case; and it is probable that the quantity of chloroform used was under-estimated.

In the fifth case, that of Mdlle. Stock, of Boulogne, death took place in nearly the same manner as in the abore cases. The surgeon said, "I placed over the nostrils of the patient a handkerchief, moistened with from fifteen to twenty drops at the most, of chloroform." It is necessary to remark, that a judicial examination of the bottle from which it had been taken, proved that from five to eight grammes had been used, a quantity equal to from 77 to 123 minims; and, as there are about four drops and a half of chloroform in each minim, the amount used was more than twenty times as great as first stated. The surgeon proceeds to say of his patient, "Scarcely had she taken several inspirations, when she put her hand on the handkerchief to withdraw it, and cried with a plaintive voice, 'I choke'. Immediately the face became pale; the countenance changed; the breathing embarrassed; and she foamed at the mouth. At the same instant (and that certainly less than a minute after the beginning of the inhalation), the handkerchief moistened with chloroform was withdrawn." 3 The operation of opening the sinus was immediately performed; but the patient showed no signs of life, and the operator believes that she was dead when he made his incision.

The only information I have met with respecting the sixth case, is that contained in the table of Bouisson previously referred to. Chas. Desnoyers, aged 22, a patient in the Hôtel Dieu at Lyons, affected with scrof plous disease of the left wrist, having to undergo transcurrent cauterisation of the joint, inhaled chloroform from an apparatus

I Ibid. p. 84.

2 Ibid. vol. xliii, p. 682.

3 Ibid. xlii, p. 211.

VoL. IV. 
for five minutes, and died at the beginning of the operation. The only particulars which are generally known of the seventh case, also, are confined to a short paragraph, which appeared in the Glasgow Herald, and was copied into the medical journals. It was stated that the patient died almost instantly after inhaling the chloroform.

Of the next case in the list, we are furnished with particulars by Dr. Warren. ${ }^{1}$ The patient was somewhat excited by the chloroform at first, but soon became tranquil; the operation of removing some hæmorrhoidal tumours was then performed. "At this moment," the surgeon says, " my attention was arrested by my assistant calling for a wet cloth : on examining the patient, I found his face and neck of a livid, leaden hue, the eyes turned upward, the pulse imperceptible at the wrist, and the whole body relaxed; after two or three gasps, he ceased to breathe." He likewise says, that "not exceeding three drachms was administered from a napkin", and that about ten minutes elapsed from the commencement of its administration before death took place."

A very precise account has been given of case number nine. ${ }^{2}$ It occurred, like the sixth case, at the Hôtel Dieu, Lyons, the subject of it being also a young man. "As usual, a piece of fine gauze was employed; it was spread over the face, leaving a free passage for atmospheric air; the chloroform was dropped from time to time upon that portion of the gauze which was over the nostrils. . . At the end of four or five minutes the patient still felt and spoke; and at the end of another minute he spoke, and was somewhat restless. Up to this time, from a drachm to a drachm and a half of chloroform had been employed. The pulse was regular, and of the normal strength. All at once the patient raised his body, and struggled so that the limbs escaped from the hold of the assistants, who, however, seized them quickly, and replaced the patient in his position. Within a quarter of a minute, one of the assistants stated that the pulse at the wrist had ceased to beat. The handkerchief was removed. The countenance was completely altered. The action of the heart had altogether ceased; the pulse could not be felt anywhere; and the sounds over the region of the heart could no longer be heard. Respiration still continued, but it became irregular, weak, and slow : and at length ceased completely, in the space of about half a minute." Various stimulants were applied to the nostrils and skin, and finally pressure was made on the chest and abdomen. "After two or three minutes, respiration reappeared, and even acquired a certain degree of fulness; but the pulse nowhere returned. Frictions were continued. Respiration became again slower, and at length ceased." In this case, we have clear proof that the action of the heart was arrested by the chloroform whilst the breathing still continued, as in the experiments Nos. 3 and 5, on animals; previously related. In this instance, the air which the patient breathed must for some time have contained very little vapour; and then it evidently became charged with it to such an extent as to so saturate the portion of blood passing through the lungs at the time, that on reaching the aorta and coronary artery, the heart became paralysed, before the sensibility of those parts of the nervous system which preside over respiration was abolished.

1 Med. Gaz. vol. xliii, p. 712.

2 Ibid. vol. xliii, p. 745, from L'Union Méd. 
In the case of Samuel Bennett, half an ounce of chloroform was "sprinkled on a handkerchief, and held over the mouth and nose... This quantity of the agent failed, however, to produce anæsthesia, having caused only the ordinary excitement and struggling". After a delay of two hours, more chloroform was procured, and half an ounce was again applied on a handkerchief, " care being taken to allow the entrance of air at short intervals". Insensibility was induced, and the toe was amputated; the chloroform being applied, as I was told, during part of the time of the operation. At the close of the operation, no blood escaped when the pressure was removed from the arteries; the patient was in fact dying, and in a short time expired. "A few inspirations were noticed after the pulse had ceased at the wrist". In this, as in two subsequent cases, the first attempt to cause insensibility failed; a circumstance which illustrates the uncertainty of the method that was employed to give the chloroform, and which affords additional proof of the fallacy of the opinion which attributes the accidents to idiosyncrasy, or peculiar susceptibility ; for it cannot be supposed that a patient could be the subject of two opposite idiosyncrasies, or could have a want of susceptibility on the first occasion, and a greater susceptibility than usual two hours afterwards.

Of the next case- that of Mdme. Labrune-we are told, " complete insensibility was not produced at the first trial : more chloroform was placed on the handkerchief, and she drew a full inspiration. Her countenance immediately became pallid; her features were visibly altered; there was dilatation of the pupils, with a convulsive rolling of the eyes; and no pulse could be felt. Every attempt was made to restore life, but without success. She died as if struck by lightning".? The instantaneous arrest of the circulation, on a full inspiration being taken, immediately after more chloroform had been placed on the handkerchief, is particularly worthy of notice. The heart was paralysed, in this instance, as quickly as in experiment No. 4, on the rabbit; and this accident, amongst others, illustrates and confirms the calculations which were made, in the former part of this paper, on the probable effects of 100 cubic inches of air, charged with ten per cent. of vapour, in the cells of the lungs.

The twelfth case occurred in St. Thomas's Hospital. The chloroform was administered by a non-medical person-a sort of surgery man. An inhaler was used, though, in my opinion, not one of the best construction. It was when Mr. Solly had just removed the toenail that the danger of the patient was perceived. "After struggling for about a minute, he became still, the skin cold, pulse scarcely perceptible, and soon ceased to be felt at the wrist; respiration became slow and at intervals, but continued a few seconds after the cessation of the pulse". The impropriety of entrusting the administration of chloroform to a non-medical person, however.able the on-lookers may be, having, I believe, been generally admitted, I need not enlarge on that point, but would obsierve that in this, as in several other cases, it was whilst the attention of every competent person present was absorbed by the operation, that the dangerous symptoms commenced.

1 Lancet, 1849, vol. i, p. 205.

2 Med. Gra., vol. xliv, p. 478, from L'Union Médicale, Sept. 8, 1849.

3 Ibid. p. 757. 
In cases 3,10 , and 16, it was the absence of bleeding which called attention to the dangerous state of the patient.

I am not aware that full particulars have ever been published of the next case, that of a girl named Jones, who was about to undergo extirpation of the eyeball. It is stated, however, that a drachm of chloroform was used, and that she expired instantaneously. ${ }^{1}$

In case fourteen, that of a young lady at Berlin, the chloroform was poured on a sponge, which was covered with a napkin. The dentist (not a medical man) made fire unsuccessful attempts to get his patient sufficiently insensible; and when he did, what was most likely to happen under such circumstances, he committed an error in the opposite direction. His patient suddenly died, almost at the commencement of his sixth attempt, stretching herself out, and frothing at the mouth, at the moment of death. There is no account of the pulse or respiration. ${ }^{2}$

The case which occurred on board ship at the Mauritius, was included in a list of deaths I made out in $1850 ;^{3}$ but I am not aware that it has been otherwise published. A report of the case was sent to the Board of Ordnance, and also to the Admiralty. I had the opportunity of reading one of these reports, through the kindness of the nobleman at the head of the department to which it was sent, and I made a note of the chief particulars, as soon as I got home. As the report was a very able one, it is to be regretted that it has not been published. The accident occurred to an artilleryman, aged 24, who required to have the last phalanx of the middle finger removed. In other respects, he was considered to be in good health. Two scruples of chloroform were first poured on the handkerchief with which it was administered, and then one scruple more. It was observed that the face turned pale, and the pulse and breathing ceased, soon after the chloroform was discontinued. The measures which were employed to restore him were of no service. The lungs, after death, were found to be emphysematous; and, upon inquiry, it was ascertained that he had been short of breath on exertion. The reporter considered that the emphysema was the cause of death, by interfering with expiration, and thus detaining the vapour; and it must be admitted that, if the vapour were not sufficiently diluted with air, the emphysema would increase the danger. At the same time, I have had practical experience to show that, when it is sufficiently diluted, it may be safely inhaled, even in extreme cases of emphysema.

The case at Guy's Hospital, is one of those in which the first endeavour to cause insensibility failed; and also one of those in which the sudden cessation of bleeding was the means of calling attention to the danger of the patient. Mr. Cock said, in his evidence at the inquest: "The ordinary machine was used, and, as it had not the effect, witness directed that a napkin should be folded into the shape of a cone, which was applied with chloroform. The operation of removing a portion of the bone occupied one minute and a half; but before it was completed, the blood which was gushing out suddenly stopped, when witness directed Mr. Lacy to feel the pulse of deceased, and they found that deceased had expired."

1 Med. Gaz. p. 1007.

3 Med. Times, vol. ii, p. 230.
2 Ibid. vol. xlv, p. 483.

1 Med. Gaz., vol. xlvi, p. 89. 
In case seventeen, which occurred at the Cavan Infirmary, a fluid drachm of chloroform was poured on a bit of lint, which was placed in a hollow sponge, and the sponge was enclosed in a towel. As there was some delay, half a drachm more was added. The patient had not taken more than fifteen inspirations after this, when the anæsthesia was said to be complete. The towel was removed from the face, a slight convulsive action of the left eyelid was observed, and there was some froth at the mouth. On a more minute examination of the patient, he was found to be dead.

There has been no full account published of the fatal case at the Stepney Workhouse. It was stated at the inquest that half a drachm of chloroform was administered without effect, and then half a drachm more was applied, when the patient suddenly expired. I was informed by a medical man, living in the neighbourhood where this case happened, that the handkerchief on which the chloroform was administered was tied behind the head of the patient; but, as my informant was not an eye-witness, I cannot state with certainty that such was the fact.

Case nineteen on the list is important, as having given rise to a prosecution. The medical man, an officier de santé, named Kobelt, was accused of homicide, by imprudence, want of precautions, etc. The chloroform was administered on a handkerchief, and the accident occurred as suddenly as any of the others. The husband of the patient stated that the whole process did not last a minute. "I observed attentively," he said, "during this time, and the character that her countenance took all at once made me apprehensive. I spoke of it to the operator, who tranquillised me, and continued to extract the teeth. After the third tooth, however, he partook of my apprehension, suspended the operation, and proceeded to adopt measures indicated by the circumstances." 1 Professor Sédillot, who had to pronounce an opinion on the case, after hearing all the evidence, expressed himself very nearly as I did, when alluding, on a former occasion, to the death which occurred in Westminster. ${ }^{2}$ He said : "I do not think that M. Kobelt is guilty of imprudence or of rashness, because that officier de santé has followed a practice very habitually employed, and even recommended, by eminent practitioners, whose example and authority were sufficient to inspire him with security, and shade him from reproach." The accused practitioner was acquitted. The above remark of Sédillot applied to the plan of causing insensibility very rapidly, as first recommended by Dr. Simpson; and he added some observations, to the effect that, when used in a different manner, chloroform is free from danger.

In the case at the Dreadnought Hospital Ship, all the precaution seems to have been taken that is possible in giving undiluted chloroform on a handkerchief; and, if the quantities that are mentioned as having been poured on were actually measured, this case would strongly confirm the opinion that insensibility cannot be caused in this way, without some degree of danger. Twenty minims, it is said, were poured upon a linen cloth. At the expiration of a few minutes, this had been dissipated, producing only very trifling excitement; a second

1 L'Union Médicale, 20 Jan. 1852. 2 Edin. Med. and Surg. Journ., No. 180. 
dose, of the same quantity, was then administered in the same way. Ten minims more were put on the handkerchief, and finally other twenty minims. When the patient was insensible, the operation was commenced; but it had proceeded only a very little way, when the flow of blood and the pulse ceased at the same moment. The breathing also stopped at the same time, but the man afterwards took one or two deep sighing inspirations. ${ }^{1}$ It is evident that the last quantity of chloroform was inhaled in a too concentrated state, and that the heart was paralysed by the absorption of vapour which was present in the lungs at the instant when the inhalation was discontinued.

We have no account of the manner in which the breathing and circulation ceased in the last case of the list, for no one. was observing the patient at the time. The chloroform was administered for the removal of impacted fæces from the rectum, a proceeding which would otherwise have been attended with great pain on account of cancerous disease in the neighbourhood. The medical attendant administered the chloroform on a handkerchief, and used altogether eight or ten drachms. He says: "When I found the arm fall after being raised (a very uncertain sign to rely on), I proceeded to and accomplished the operation. At this time she was not inhaling." On turning his attention again to the state of his patient he found that she was dead. ${ }^{2}$

Since the former part of this paper was sent to the press a fatal accident has unfortunately happened, in St. Bartholomew's Hospital, to a young man, aged 23, affected with aneurism by anastomosis of the right ear and surrounding soft parts. Mr. Lloyd, having tied the temporal artery the week before, under the influence of chloroform, with advantage, was proceeding to tie an artery between the mastoid process and ramus of the jaw, when the patient suddenly expired from the effect of the chloroform, which was administered by one of the dressers with an apparatus which had been used on the former occasion. In from five to ten minutes the usual effect was produced, the patient having previously struggled much. The operation was then commenced; but no sooner had Mr. Lloyd cut through the skin than it was stated that the pulse had suddenly ceased. The chloroform was at once removed, but in a few seconds the patient had ceased to breathe, and no pulsation could be felt in any of the arteries, or at the heart. ${ }^{3}$ Under the use of compression, percussion, and other means, the act of respiration was several times performed again, on two occasions, and it is stated that " the circulation was observed to be returning." I I understand that the red colour returned to the face, but have not learnt whether the pulse or action of the heart was distinctly felt or heard. The respiration might cause the colour to return to the face without a true circulation, as I have seen whilst inflating the lungs of still-born children; for if a portion of red blood be mechanically displaced from the lungs by the motion of the chest, it will be sent on by the contractility of the arteries, which continues for some time after death. If the heart had recommenced to beat, complete recovery would most likely have taken place, for such has

1 Med. Times, 1851 , vol. ii, p. 98.

3 Med. Times and Gaz., p. 203.
2 Ibid., 1851, vol. ii, p. 620.

1 Loc. cit. 
been the result, under similar circumstances, in the observations I have made on animals.

I have been kindly informed by Mr. Paget of a death from chloroform, with which I was previously unacquainted. It occurred on May 22nd, 1850, in the practice of Professor Carl Santesson, in the Seraphim Hospital at Stockholm. In this case also the heart was paralysed by the direct action of the chloroform, and the breathing continued after the heart had ceased to beat; as in some of the other cases. The patient, a man thirty years of age, was affected with hydrocele, and there was some suspicion of disease of the testicle. It was consequently intended to operate on the hydrocele by incision, in order that the testicle, if diseased, might be removed. The chloroform was administered in the same way that Professor Santesson had seen it exhibited by Dr. Simpson, except that it was poured on a little cotton, which was placed at the small end of the cone, into which the folded towel he made use of was rolled. About a drachm and a half was first poured on the cotton, and the patient was told to inhale in long and deep inspirations. This quantity being nearly evaporated in two or three minutes, a drachm more was added. After a few inspirations rigidity and struggling came on: these subsided, but in a little time returned more strongly than before, and the towel was removed from the face until the struggling ceased. The patient, however, not being sufficiently insensible to undergo the operation with the necessary quietness, the towel was reapplied, when, after a few inspirations, the pulse suddenly ceased. The face and the whole surface of the body turned pale, the eyes rolled upwards and inwards, and the breathing became very slow, but full and deep, the intervals between the inspirations becoming longer, until the respiration ceased altogether. The patient died before the operation was begun, and within five minutes from the commencement of inhalation. During the application of various means of resuscitation, including the dropping of cold water guttation on the epigastrium, the breathing returned, and continued for the space of three or four minutes; but the pulse and sounds of the heart did not return.

The above particulars of the mode in which death took place in the various cases of accident, when considered in connexion with the experiments on animals described at the commencement of the paper, show clearly enough that in every instance the air breathed by the patient just before death, was too highly charged with chloroform to be consistent with safety; for if the air contain not more than about five per cent. of vapour, symptoms of danger would exist for a considerable time before death; and even should the inhalation be continued till the patient ceased to breathe, the action of the heart would survive the respiration-a circumstance which has not been observed in any of the fatal cases.

(To be continued.) 